\title{
Treatment of Spilled Auto-Mechanic Garage Oils in Soil Using Polyethylene Terephthalate (PET) Waste Materials
}

\author{
John Stephen Gushit*, Victor Fedoje Oguche, Idoko Ogbe \\ Department of Science Laboratory Technology, Faculty of Natural Sciences, University of Jos, Jos, Plateau State, Nigeria \\ Email address: \\ gushitj@unijos.edu.ng (J. S. Gushit),oguvictor2014@gmail.com (V. F. Oguche), idokoo@unijos.edu.ng (I. Ogbe) \\ ${ }^{*}$ Corresponding author
}

\section{To cite this article:}

John Stephen Gushit, Victor Fedoje Oguche, Idoko Ogbe. Treatment of Spilled Auto-Mechanic Garage Oils in Soil Using Polyethylene Terephthalate (PET) Waste Materials. Science Journal of Analytical Chemistry. Vol. 8, No. 3, 2020, pp. 117-121.

doi: $10.11648 /$ j.sjac.20200803.15

Received: August 9, 2020; Accepted: August 26, 2020; Published: September 3, 2020

\begin{abstract}
The work aimed at cleaning oil contaminated soil started with sorting and pulverizing pre-clean high density polyethylene terephthalate (PET) waste materials. The soil samples were collected from Farin-Gada Auto-Mechanic village located at Jos North Local Government area, Plateau State-Nigeria. They were prepared by homogenizing, crushing and sieving (mesh size $\leq 2 \mathrm{~mm}$ ), then extracted and purified for characterization of the total petroleum hydrocarbon (TPH) using gas chromatography mass spectroscopy (GCMS). For the heavy metals, the soil samples were air-dried, digested using mineral acids $\left(\mathrm{HNO}_{3}\right.$ and $\left.\mathrm{HCl}\right)$ in appropriate proportion, then analyzed using atomic absorption spectrophotometer (AAS). The levels of nickel $(\mathrm{Ni})$, lead $(\mathrm{Pb})$, chromium $(\mathrm{Cr})$, cadmium $(\mathrm{Cd})$ and $\mathrm{TPH}$ were assessed in the sample used as control (uncontaminated) labelled as 'CC-S'. Untreated soil (automobile mechanic garage soil) labelled 'UT-S', and treated soil labelled as 'TT-S. The results revealed that the untreated soil (UT-S) had high contaminants when compared to that of CC-S and TT-S. This suggest that anthropogenic activities is the major source of the soil contamination. On treating the contaminated soil with PET, the concentration of $\mathrm{Ni}, \mathrm{Pb}, \mathrm{Cr}$ and $\mathrm{Cd}$ in the UT-S was reduced by $18 \%, 4 \%, 84 \%$ and $66 \%$ respectively. Similarly, the total petroleum hydrocarbon (TPH) concentration reduced from $0.271 \mathrm{mg} \mathrm{kg}^{-1}$ to $0.082 \mathrm{mg} \mathrm{kg}^{-1}$ on treating UT-S with PET. The present work has established that pulverized waste polyethylene terephthalate (PET) can be processed and used to clean up oil contaminated soils.
\end{abstract}

Keywords: Treatment, Oil Contaminated Soil, Polyethylene Terephthalate (PET), Heavy Metals, Total Petroleum Hydrocarbon (TPH)

\section{Introduction}

Crude oil products are one of the common environmental contaminants/pollutants, and its spillage has a hazardous effect on both plants and animals living within the natural environment. However, the current rapid rate of industrialization, urbanization [1] and economic activities like mining [2], agriculture [3], industries and transportation [4, 5], can lead to contamination of environmental resources due to huge amount of waste they generate. For instance, gasoline, battery manufacture, metal plating, smelting, tanneries, petroleum refining, paint manufacture, pesticide, cosmetics, ceramics, pigment manufacture, printing and photographic industries, etc., are sources of 0 heavy metals such as cadmium, zinc, copper, nickel, lead, mercury, cobalt, manganese and chromium [6].

Also, spills from used automobile oils, worn machinery, used batteries, organic and inorganic chemicals used in oil as additives also release different heavy metals [7], and these heavy metals enter the environment through bio-magnifications in food chains [8]. Once these toxic substances penetrate into the ground, they have the capacity to pose a wide range of adverse environmental problems [9, 10]. For instance, a study [11] confirmed that garage and automotive workers are in danger of impending lead toxicity and facing abdominal colic, constipation, and central nervous system dysfunction. Other studies [12, 13] further confirmed that plants and leafy vegetables grown using wastewater and 
polluted soil can accumulate toxic heavy metals above maximum limit [14], causing serious risk to human health when consumed [15].

In recent times, Shashemane City is characterized as one of the fastest growing cities and center of business in Oromia region. This will lead to rapid increase in automobile garage villages, and the implication of this is releases of different types of used lubricants and oil related pollutants that have significant potential impact into the environmental sectors [16] undertaking different operational activities. Mindful of the impact of activities in garages, an investigation [11] on impact of exposure to lead $(\mathrm{Pb})$ by garage workers which relates to a similar study [13] in which it was discovered the effects of oil spills are not limited to the immediate environment alone. The immediate effects on humans, fish, animals, birds and wildlife in general, mainly are due to; direct contact with the spilled oil including breathing of volatilized oil components from the spillage, direct contact with the environment polluted with spilled oil components, such as drinking polluted water or breathing polluted dust particles and consumption of polluted food at any level within the food chain, with a higher risk for food pollution at the higher levels of the food chain i.e. humans and animals. Hence, the need to clean contaminated soils, that inform the need for this work which aims to prepare as readily available waste materials to treat soil polluted by used oil and lubricants.

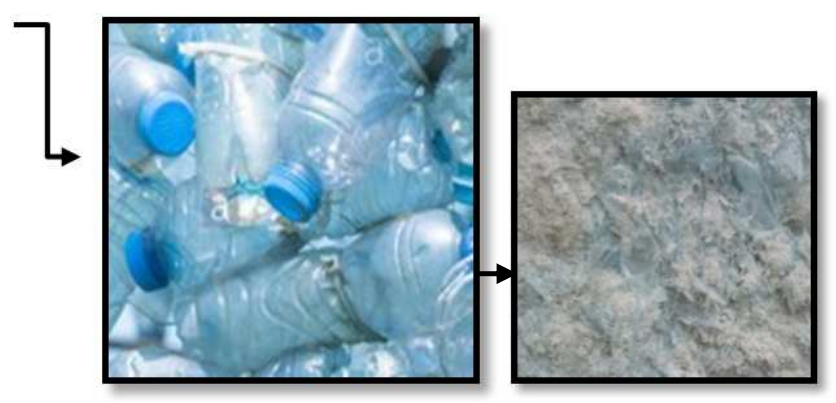

Figure 1. Pulverized high density PET materials.

\section{Materials and Experiments}

\subsection{Study Area}

Jos North is located in the Northern part of Plateau State situated between Latitudes $9^{\circ} 56^{\prime} 21.7^{\prime \prime}\left(9.9394^{\circ} \mathrm{N}\right)$ and Longitudes $8^{\circ} 5^{\prime} 8^{\prime \prime}\left(8.9022^{\circ} \mathrm{E}\right)$, elevation 1,200 meter $(3,937$ feet). The mechanic garage village being studied is located along Farin-Gada Jos North Local Government, Plateau State, Nigeria (Figure 2). It covers a large span of land, a busy area where automobile repairs and maintenance are carried out and serves as the major mechanic workshop for the Jos metropolis and other neighboring Local Governments and States [18]. Soil exposed to petroleum hydrocarbon and heavy metal contamination due to industrials activity and transportation was collected at different depth of $(0.5 \mathrm{~m}$ and $1.0 \mathrm{~m})$ from the automobile repair workshops close Farin-Gada Market.

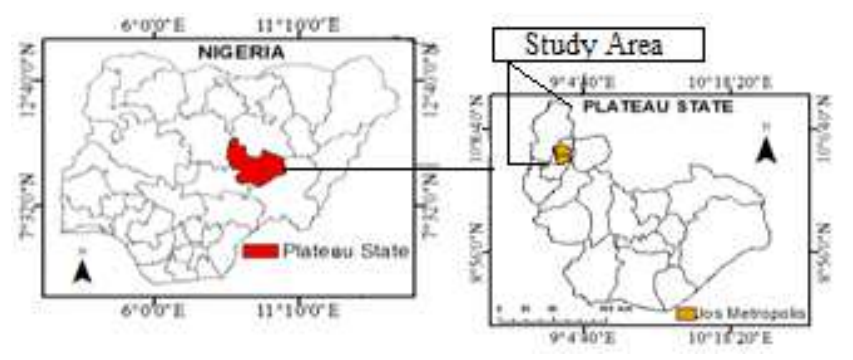

Figure 2. Location of the study area.

\subsection{Sampling Area}

The study was done by obtaining samples from Farin-Gada Auto-Mechanic Village, Jos North Local Government area in Plateau State-Nigeria. It is a densely populated area where commercials maintenance of vehicles and other automobiles are done. It is located on latitude $9^{\circ} 56^{\prime} 21.7^{\prime \prime N}$ North and longitude $8^{\circ} 54^{\prime} 8^{\prime \prime}$ East of Greenwich meridian. The soil samples site location were recorded using a Geographical Positioning System (GPS), which provides precise location of the research area [19].

\subsection{Soil Samples Collection}

The soil samples were collected with the aid of a stainless steel sampling auger at different depth in amber bottles, that had been properly cleaned before soaking in $10 \%$ nitric acid and rinsed with distilled water. The sampling auger was washed with distilled water each time it is used for collection of sample before using it to collect another samples. Samples were then transported to the laboratory in clean plastic coolers and stored in the chiller awaiting analysis.

\subsection{Sample Treatment Using the Pulverized PET Material}

A reasonable quantity of high density polyethylene terephthalate (PET) waste polymeric bottles with properties earlier identified (Table 3) [20] were collected and clean before pulverizing into powder (mesh size $\leq 2.00 \mathrm{~mm}$ ) using the Cryo-milling technique under specified conditions [17]. It was also tested to ascertain the safety usage of the PET rubber, and to ensure that all PET rubber used does not serve as a contaminating agent other than the purpose it was employed for [21]. $50 \mathrm{~g}$ of the polluted soil sample and $10 \mathrm{~g}$ of the pulverized material (PET powder) was measured into $200 \mathrm{ml}$ of distilled water in a $500 \mathrm{ml}$ beaker. On stirring, the processed PET absorbed the oil contaminants which are hydrocarbon in nature, then scooped. A portion of the soil left was dried and digested for heavy metals analysis, while the second portion was used for Total Petroleum Hydrocarbon (TPH) analysis. The material used in this research work was polymeric materials that had been properly cleaned by soaking in 3\% nitric acid, thereafter rinsed with distilled water.

\subsection{Heavy Metals Analysis}

The dried soil samples were ground and sieved through $\leq$ $2 \mathrm{~mm}$ mesh-sized sieve mesh. $1.00 \mathrm{~g}$ of each of the sieved sample was weighed into an Erlenmeyer flask, and $100 \mathrm{ml}$ of 
distilled water added. $0.5 \mathrm{ml}$ of Nitric acid $\left(\mathrm{HNO}_{3}\right)$ and $5 \mathrm{ml}$ of Hydrochloric acid $(\mathrm{HCl})$ was added in the ratio of $1: 10$ and swirl vigorously. This was heated to digest until it became clear. The resulting solution was filtered through what-mann filter paper into a $100 \mathrm{ml}$ volumetric flask. The samples were turned into $100 \mathrm{ml}$ plastic bottles and analysed using Atomic Absorption spectrophotometer (Perkin-Elmer, Model 2380).

\subsection{Total Petroleum Hydrocarbon (TPH) Analysis}

The wet soil sample was air-dried and homogenized, after which the sample was crushed and filtered. $10.00 \mathrm{~g}$ portion of the sample was weighed into the brown laboratory amber bottles. Thereafter $10 \mathrm{ml}$ of a mixture of Dichloromethane (DCM) and Acetone in the ratio of 1:1 added to the sample. A known concentration of O-terphenyl standard was also measured into the sample to help spike the samples. The mixture were further agitated using the vortex mixer for 20 minutes. This was then filtered using whatmann filter papers on a reasonable amount of anhydrous sodium sulphate $\left(\mathrm{Na}_{2} \mathrm{SO}_{4}\right)$. The samples were then collected and further filter through a micro column parked with cotton wool and silica gel powder (60-120 mesh size). Anhydrous sodium sulphate $\left(\mathrm{Na}_{2} \mathrm{SO}_{4}\right)$ was further added on the silica gel inside the column as drying agent before the sample was passed through it. The purified samples were finally concentrated to $3 \mathrm{ml}$ before detecting them using Gas Chromatography-Mass Spectroscopy (GC-MS).

\section{Result and Discussion}

Heavy Metals and TPH concentrations in the Control
(CC-S), Untreated (UT-S) and Treated samples (TT-S) are shown in Tables 1 and 2, with their corresponding graphs in Figures 4 and 5. Similarly, the TPH spectra of the TT-S and UT-S extracts are indicated in Figure 6 obtained by direct infusion of the purified extracted sample into the Gas Chromatography Mass Spectrometer (GC-MS).

\subsection{Heavy Metals And Total Petroleum Hydrocarbon Concentrations}

The Control (CC-S), Treated (TT-S) and Untreated (UT-S) soil samples under investigation revealed varying concentrations of all the four heavy metals $(\mathrm{Ni}, \mathrm{Pb}, \mathrm{Cr}$, and $\mathrm{Cd})$ analyzed. The concentrations were in the range of 0.025-0.039 $\mathrm{mg} \mathrm{kg}^{-1}$ for $\mathrm{Ni}, 0.080-0.206 \mathrm{mg} \mathrm{kg}^{-1}$ for $\mathrm{Pb}, 0.090-1.280 \mathrm{mg}$ $\mathrm{kg}^{-1}$ for $\mathrm{Cr}$ and $0.002-0.009 \mathrm{mg} \mathrm{kg}-1$ for $\mathrm{Cd}$ as shown in Table 1. The relatively unpolluted soil (from a conserved area within University of Jos) representing the 'Control sample' showed a concentration of $0.025 \mathrm{mg} \mathrm{kg}^{-1} 0.080 \mathrm{mg} \mathrm{kg}^{-1} 0.090 \mathrm{mg} \mathrm{kg}^{-1}$, and $0.002 \mathrm{mg} \mathrm{kg}^{-1}$ for $\mathrm{Ni}, \mathrm{Pb}, \mathrm{Cr}$ and $\mathrm{Cd}$ respectively. While for the polluted area, which represent untreated soil (automobile mechanic garage soil) labelled 'UT-S' had the concentration of $\mathrm{Ni}, \mathrm{Pb}, \mathrm{Cr}$ and $\mathrm{Cd}$ to be $0.039 \pm 0.01,0.206$ $\pm 0.03,1.280 \pm 0.14$ and $0.009 \pm 0.06 \mathrm{mg} \mathrm{kg}^{-1}$ respectively. On treating the soil, the concentrations of all these metals reduced significantly. From this, the concentrations of $\mathrm{Ni}$ and $\mathrm{Pb}$ reduced by $18 \%$ and $4.00 \%$ respectively. Higher reduction was observed in $\mathrm{Cr}$ with $84 \%$ and $\mathrm{Cd}$ with $66 \%$ (Table $1 \&$ Figure 3). This suggest the treatment method used in this research is effective and can even be adopted at a larger scale to treat similar oil contaminated soils.

Table 1. Heavy Metal concentration $(X \pm S D)(\mathrm{mg} / \mathrm{kg})$ in the Control (CC-S), Untreated (UT-S) and Treated (TT-S) Soil Samples.

\begin{tabular}{lllll}
\hline Sample Code & Ni & Pb & Cr & Cd \\
\hline CC-S & $0.025 \pm 0.04$ & $0.080 \pm 0.08$ & $0.090 \pm 0.06$ & $0.002 \pm 0.02$ \\
UT-S & $0.039 \pm 0.01$ & $0.206 \pm 0.03$ & $1.280 \pm 0.14$ & $0.009 \pm 0.06$ \\
TT-S & $0.032 \pm 0.04$ & $0.198 \pm 0.06$ & $0.199 \pm 0.17$ & $0.003 \pm 0.01$ \\
Quantity Removed & 0.007 & 0.008 & 1.081 & 0.006 \\
\% Removed & 18.00 & 04.00 & 84.00 & 66.00 \\
\hline
\end{tabular}

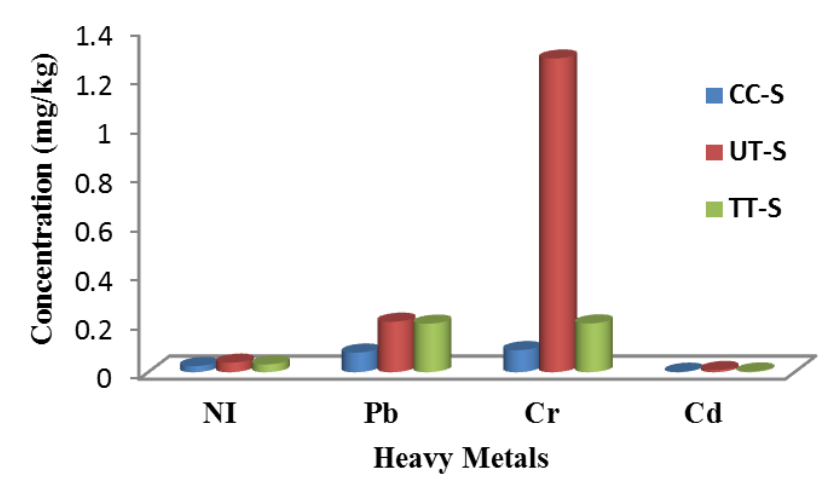

Figure 3. Heavy Metals Concentration ( $\mathrm{mg} / \mathrm{kg})$ in Control (CC-S), Untreated (UT-S) and Treated (TT-S) Soil Samples.

\subsection{Total Petroleum Hydrocarbon (TPH) Concentrations}

From this work, the total petroleum hydrocarbon (TPH) concentration lies between $0.002-0.174 \mathrm{mg} \mathrm{kg}^{-1}$ in the auto-mechanic garage contaminated soil (UT-S). This is quite low when compared with range for a similar work of 486 to $4,438.7 \mathrm{mg} \mathrm{kg}^{-1}$ at $0-15 \mathrm{~cm}$ depth reported in a similar work [22]. From this, there is a ray of hope as the relatively low concentration obtained in this work will pave way to regulate the contamination before it gets out of place, even though it is slightly higher than the TPH concentration of $0.002-0.153 \mathrm{mg}$ $\mathrm{kg}^{-1}$ present in the control sample (CC-S). Giving the trends of contamination widely reported in other places and sites involved in related activities. For instance, and earlier work [23] reported TPH concentrations at Petrol Stations had minimum of $399.83 \pm$ 106.19 and maximum of $450.83 \pm 90.58 \mathrm{mg} \mathrm{kg}^{-1}$ and Mechanic workshops with $362.60 \pm 185.84$ and $428.55 \pm 119.00 \mathrm{mg} \mathrm{kg}^{-1}$. This research employed a treatment approach that used high density PET to treat the contaminated soil (UT-S) from which the treated sample (TT-S) significantly recorded a low concentration of $0.081 \mathrm{mg} \mathrm{kg}^{-1}$ (Table 2 and Figure 5).

Table 2. Profile and concentration $(\mathrm{mg} / \mathrm{kg})$ of TPH in the Control (CC-S), 
Untreated (UT-S) and Treated (TT-S) Soil Samples.

\begin{tabular}{llll}
\hline Compounds & CC-S & UT-S & TT-S \\
\hline Decane & 0.002 & 0.004 & 0.002 \\
Undecane & 0.002 & 0.001 & 0.000 \\
Tridecane & 0.001 & 0.002 & 0.001 \\
Tetradecane & 0.008 & 0.010 & 0.000 \\
Pentadecane & 0.004 & 0.008 & 0.002 \\
Hexadecane & 0.001 & 0.001 & 0.000 \\
Heptadecane & 0.002 & 0.003 & 0.001 \\
2,6,10,14-tetramethyl-pentadecane & 0.001 & 0.000 & 0.000 \\
1,2-dimethyl-cyclooctane & 0.153 & 0.175 & 0.046 \\
Octadecane & 0.022 & 0.036 & 0.003 \\
Nonadecane & 0.001 & 0.007 & 0.005 \\
Eicosane & 0.001 & 0.003 & 0.002 \\
Heneicosane & 0.007 & 0.013 & 0.008 \\
Hexacosane & 0.002 & 0.008 & 0.007 \\
Tetracosane & 0.001 & 0.002 & 0.002 \\
Octacosane & 0.000 & 0.000 & 0.002 \\
9-octyl-Heptadecane & 0.000 & 0.001 & 0.000 \\
7-hexyl-Docosane & 0.000 & 0.000 & 0.001 \\
\hline
\end{tabular}

Table 3. Properties of PET used.

\begin{tabular}{ll}
\hline Property & Value \\
\hline Density & 0.93 to $0.97 \mathrm{~g} / \mathrm{cm}^{3}$ \\
Chemical Property & Inert \\
Heat Resistant & $>100^{\circ} \mathrm{C}$ \\
Melting Point & $135^{\circ} \mathrm{C}$ \\
\hline
\end{tabular}

Source [20].

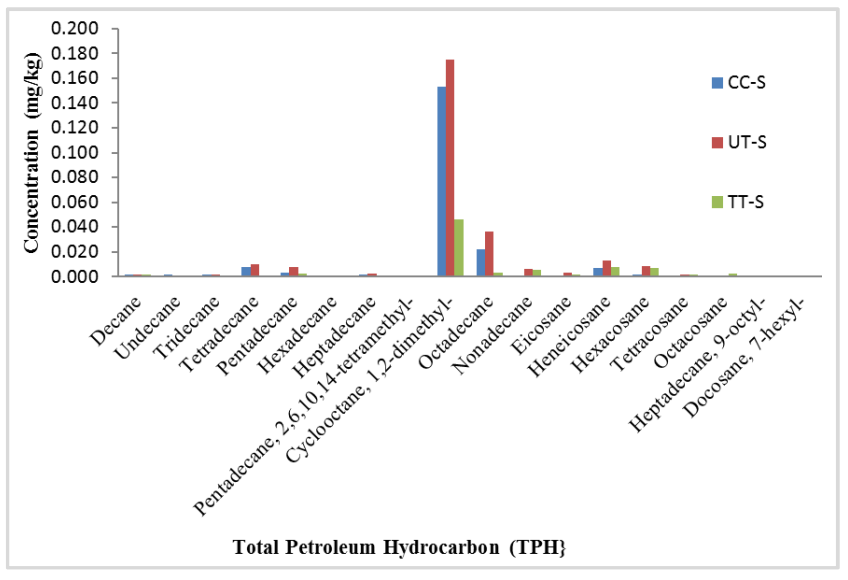

Figure 4. TPH'S Concentration ( $\mathrm{mg} / \mathrm{kg})$ in Control (CC-S), Untreated (UT-S) and Treated (TT-S) Soil Samples.

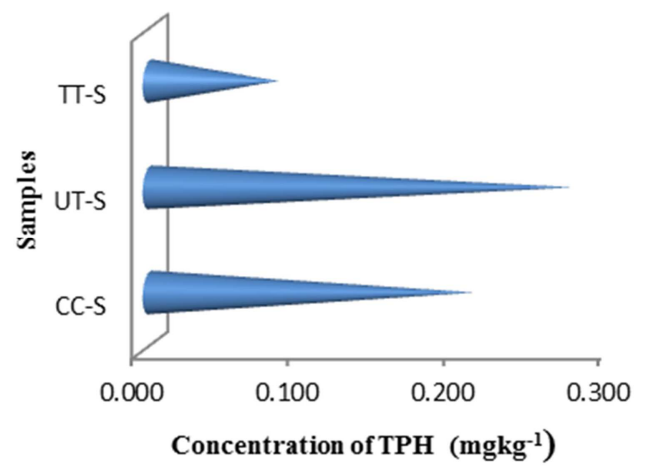

Figure 5. Summary Concentration of THP in Control (CC-S), Untreated (UT-S) \& Treated (TT-S) Samples.

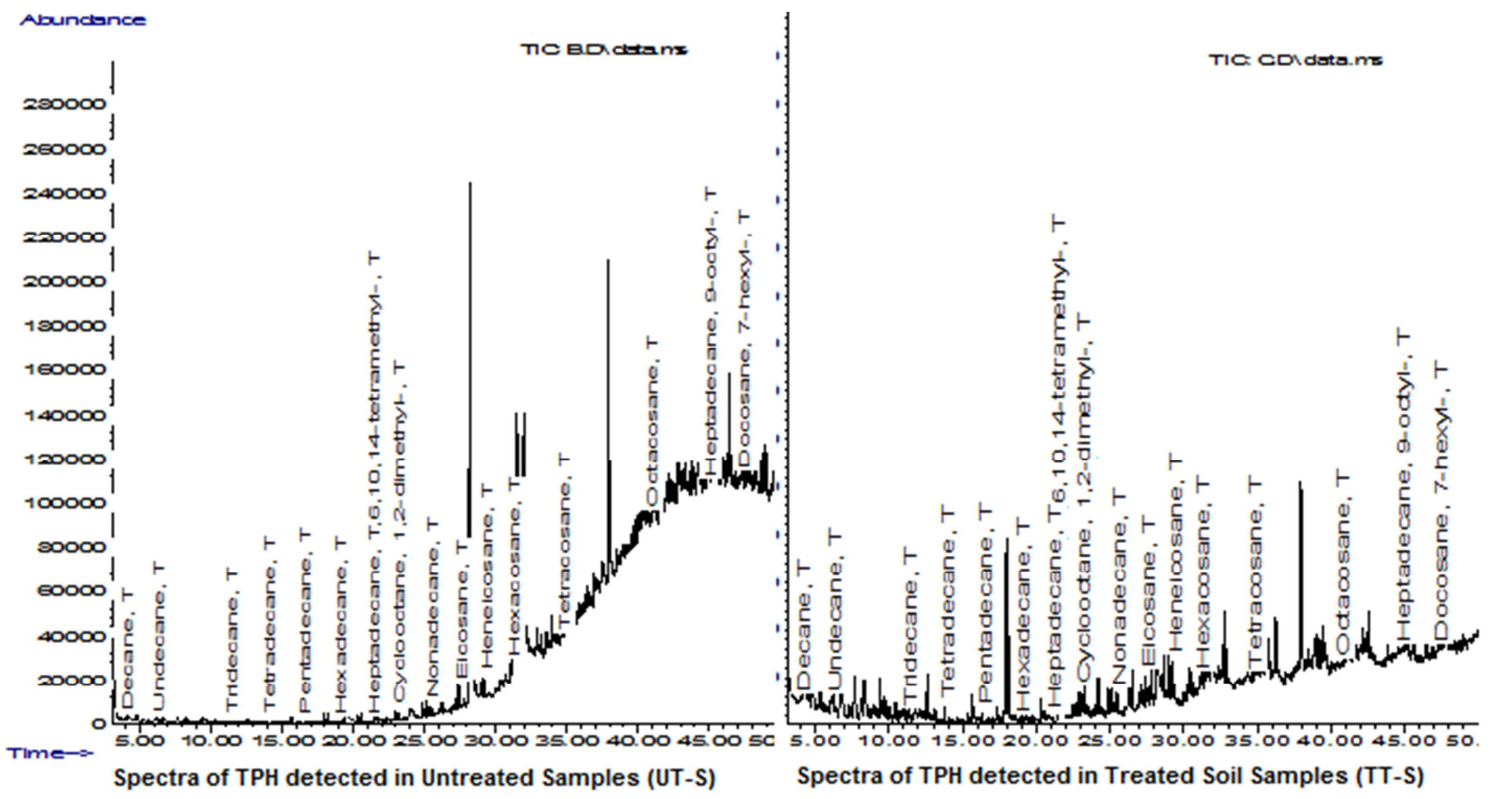

Figure 6. Spectra for the direct infusion of Treated (TT-S) and Untreated Soil Samples (UT-S).

\section{Conclusion}

Pulverized high density polyethylene terephthalate (PET) waste bottles used for cleaning oil and lubricant contaminated soil was found to be effective, as considerable quantity of pollutants like
TPH were removed from the contaminated soil by $70 \%$. While heavy metals like $\mathrm{Cr}$ and $\mathrm{Cd}$ were significantly cleaned up by $84 \%$ and $66 \%$ respectively. This goes on to give positive indication that waste PET materials instead of being environmental nuisance, can be processed to clean up these categories of pollutants in oil 
polluted soils. In addition, to deal with the problem from the root, it is advisable that all automobile repairs done in different cities be restricted to mechanic villages, to enhance ease of collection, preservation, recycling and re-use of spent oils. This will put an end to indiscriminate disposal of spent automobile oils which results in excessive pollution of topsoil.

\section{Acknowledgements}

We are grateful to the Department of Chemistry and Science Laboratory Technology of University of Jos for allowing us have free access to their laboratory facilities to conduct this research.

\section{References}

[1] Jiang. M., Zeng, G., Zhang, C., Ma. X., Chen, M., Zhang, J., Lu, L., Yu, Q., Hu, L., \& Liu, L. (2013). Assessment of heavy metal contamination in the surrounding soils and surface sediments in Xiawangang River, Qingshuitang District. PLoS One 8 (8): e71176. doi: 10.1371/journal.pone.0071176.

[2] Navarro, M., Pérez-Sirvent, C., Martínez-Sánchez, M., Vidal, J., Tovar, P. and Bech, J. (2008). Abandoned mine sites as a source of contamination by heavy metals: a case study in a semi-arid zone. Journal of Geochemical and Exploration, 96 (2-3): 183-193.

[3] Vaalgamaa, S. and Conley, D. (2008). Detecting environmental change in estuaries: nutrientand heavy metal distributions in sediment cores in estuaries from the Gulf of Finland. Baltic Sea. Estuarine Coast Shelf Science, 76 (1): 45-56.

[4] Jaradat, Q., Masadeh, A., Zaitoun, M. and Maitah, B. (2005). Heavy metal contamination of soil, plant and air of scrapyard of discarded vehicles at Zarqa City, Jordan. Soil Sediment Contaminations, 14: 449-462.

[5] David, O. and Sunday, A. (2012). Assessment of vehicular pollution of road side soilsin Ota metropolis, Ogun State, Nigeria. International Journal of Civil and Environmental Engineering, 12 (4): 40-46.

[6] B. J. Alloway, Soil pollution and land contamination. In: Harrison RM (ed) Pollution: causes, effects and control. The Royal Society of Chemistry, Cambridge, 1995, pp 318.

[7] European Environment Agency (EEA) (2007). Progress in management of contaminated sites (CSI 015). EEA. Assessment Published July 2005; Kongenytorv, 6DK-1050, Denmark. http://www.eea.europa.au.

[8] H. Bradl, Heavy metals in the environment: origin, interaction and remediation. Elsevier Academic press, London, 2005, pp. $1-282$.

[9] Tamene, F. D. (2008) Assessment of lead toxicity awareness among battery charging garage and workshop workers and levels of lead in piped drinking water of Addis Ababa, Ethiopia http://etd.aau.edu.et/dspace/items-by-author=Tamene $\% 2 \mathrm{C}+$ Fit e.
[10] Cai, J., Cao, Y., Tan. H., Wang, Y. and Luo, J. (2011). Fractionation and ecological risk of metals in urban river sediments in Zhongshan City, Pearl River Delta. Journal of Environmental Monitoring. 13 (9): 2450-2456.

[11] Adela, Y., Ambelu, A. and Tessema, D. (2012). Occupational Lead exposure among automotive garage workers a case study for Jimma town. Journal of Occupation and Medical Toxicology, 7 (1), 15: 1-8.

[12] Naser, H., Sultana, S., Mahmud, N., Gomes, R. and Noor, S. (2011). Heavy metal levels in vegetables with growth stage and plant species variation. Bangladesh Journal of Agricultural Resources, 36 (4): 563-574.

[13] Itanna, F. (2002). Metals in leafy vegetables grown in Addis Ababa and toxico-logical implications. Ethiopia Journal of Health and Development, 16 (3): 295-302.

[14] FAO (1985). Water quality for agriculture Irrigation Drain, 29 (1): $1-120$.

[15] Akinola, M. O., Njoku K. L. and B. E. Ekeifo (2008). Determination of lead, cadmium and chromium in the tissue of an economically important plant grown around a textile industry at Ibeshe, Ikorodu area of Lagos State, Nigeria. Advances in Environmental Biology Journal, 2: 25-30.

[16] Adie, G. U. and Osibanjo, O. (2009). Assessment of soil pollution by slag from an automobile battery manufacturing plant in Nigeria. Africa Journal of Environmental Science and Technology, 3 (9): 239-250.

[17] Giri, A., Kellogg, F., Cho, K. and Pepi, M. (2014). Powder Production from Waste Polyethylene Terephthalate (PET) Water Bottles. Army Research Laboratory, pg. 1-14.

[18] F. O. Apeh (2018). "Termite (Infraorder Isoptera) As Bio-indictors Of Heavy Metal Pollution in the Environment". Department of Science Laboratory Technology, Faculty of Natural Sciences, University of Jos (Unpublished).

[19] Sankaran, S., S. Sonkamble, K. Krishnakumar and N. C. Mondal (2012). Integrated approach for demarcating subsurface pollution and saline water intrusion zonesinSIPCOT area: a case study from Cuddalorein-Southern India. Environmental Monitoring and Assessment, 184: 5121-5138.

[20] https://www.ausetute.com.au/polythen.html

[21] Dutra, C., M. T. de Alvarenga Freire, C. Nerin, K, Bentayeb, A, Rodriguez-Lafuente, M. Aznar and F. G. R. Reyes (2014). Migration of residual nonvolatile and inorganic compounds from recycled post-consumer PET and HDPE. Journal of the Brazilian Chemical Society, 25 (4): 686-696.

[22] Chukwujindu, M. A., E. S. Iwegbue and G. E. W. Nwajei (2008). Characteristic levels of total petroleum hydrocarbon in soil profiles of automobile mechanic waste dumps. International Journal of Soil Science, 3 (1): 48-51.

[23] Adeniyi, A. A. and J. A. Afolabi (2002). Determination of total petroleum hydrocarbons and heavy metals in soils within the vicinity of facilities handling refined petroleum products in Lagos metropolis. Environ International, 28 (1-2): 79-82. 